Revista Grifos - Unochapecó

\title{
PERCEPÇÕES SOBRE O EMPODERAMENTO SOCIOECONÔMICO E PSICOSSOCIAL DE AGRICULTORAS PARTICIPANTES DE CADEIAS CURTAS ALIMENTARES
}

\author{
PERCEPTIONS ABOUT THE SOCIO-ECONOMIC AND PSYCHOSOCIAL EMPOWERMENT OF \\ WOMEN FARMERS PARTICIPATING IN SHORT FOOD SUPPLY CHAINS
}

\section{PERCEPCIONES SOBRE EL EMPODERAMIENTO SOCIOECONÓMICO Y PSICOSOCIAL DE LAS AGRICULTORAS QUE PARTICIPAN EN CIRCUITOS CORTOS ALIMENTARIOS}

\author{
Milena Demetrio ${ }^{1}$ \\ https://orcid.org/0000-0001-7975-8102 \\ Simão Ternoski \\ https://orcid.org/0000-0003-1227-7966 \\ Marcio Gazolla ${ }^{3}$ \\ https://orcid.org/0000-0002-4807-6683
}

Submissão: 07/12/2020 / Aceito: 23/02/2021 / Publicado: 31/03/2021.

\begin{abstract}
Resumo
Esta pesquisa aborda o empoderamento das mulheres do campo do Paraná que participam de cadeias curtas de comercialização de alimentos. O problema de pesquisa questiona: as mulheres da agricultura familiar se reconhecem como agentes econômicas produtivas? $\mathrm{O}$ objetivo consiste em analisar as percepções das mulheres ligadas a Associação dos Produtores Feirantes de Guarapuava (APROFEG) sobre o seu empoderamento socioeconômico e psicossocial e o papel das políticas públicas locais nestes processos sociais. Com base na crítica à invisibilidade do trabalho doméstico e de cuidados desempenhado historicamente pelas mulheres, a pesquisa busca entender como as mulheres do campo se percebem dentro do sistema familiar e de produção onde estão inseridas e se conseguem reconhecer seu trabalho como produtivo e não somente "ajuda" ao esposo/família. A metodologia foi de caráter quali-quantitativo, feita a partir da aplicação de 9 (nove) entrevistas estruturadas e 3 (três) semiestruturadas sobre três dimensões norteadoras: socioeconômica, qualidade de vida e dignidade, todas realizadas no Município de Guarapuava/PR, em 2019. Também foram entrevistados o Secretário Municipal de Agricultura e a Nutricionista da secretaria. Os resultados demonstram que as mulheres deste grupo se reconhecem como agentes econômicas produtivas quando se identificam como "agricultoras" e que têm certo grau de empoderamento. A pesquisa identificou que as políticas públicas do município, alinhadas a mudanças institucionais, podem ser mecanismos de emancipação destas mulheres.
\end{abstract}

\footnotetext{
${ }^{1}$ Bacharela em Ciências Econômicas. Mestranda do Programa de Pós-Graduação em Desenvolvimento Regional (PPGDR) da Universidade Tecnológica Federal do Paraná (UTFPR). E-mail: mih.demetiro@gmail.com

${ }^{2}$ Mestre em Desenvolvimento Regional. Professor da Universidade Estadual do Centro-Oeste (UNICENTRO). Delegado do Conselho Regional de Economia - Região Guarapuava. E-mail: sternoski@ unicentro.br

${ }^{3}$ Doutor em Desenvolvimento Rural. Professor da Universidade Tecnológica Federal do Paraná (UTFPR)/Programa de Pós Graduação em Desenvolvimento Regional (PPGDR). Líder do Grupo de Estudos e Pesquisas em Desenvolvimento, Alimentação, Mercados e Políticas Públicas (GePPADeM). E-mail: marciogazolla1@utfpr.edu.br
} 
Palavras-chave: Economia Feminista. Desenvolvimento Rural e Regional. Agricultura Familiar. Cadeias Curtas Alimentares.

\begin{abstract}
This research addresses the empowerment of women in the Paraná countryside who participate in short food marketing chains. The research question: do women in family farming recognize themselves as productive economic agents? The objective is to analyze women's perceptions linked to the Association of Guarapuava Trade Producers (APROFEG) about their socioeconomic and psychosocial empowerment and the role of local public policies in these social processes. Based on the criticism of the invisibility of domestic work and care historically performed by women, the research seeks to understand how women in the field perceive themselves within the family and production system where they are inserted, and if they can recognize their work as productive and not only "help" the spouse. The methodology was qualitative-quantitative, made from the application of 9 (nine) structured interviews and 3 (three) semi-structured about three structuring dimensions: socioeconomic, quality of life, and dignity, all carried out in the municipality of Guarapuava/PR, in 2019. The Municipal Secretary of Agriculture and the Nutritionist of the secretariat were also interviewed. The results show that the women in this group recognize themselves as productive economic agents when they identify as "farmers" and have a certain degree of empowerment. The research identified that the municipal public policies, aligned with institutional changes, can be the emancipation of these women.
\end{abstract}

Key words: Feminist Economics; Rural and Regional Development; Family Agriculture; Short Food Supply Chains.

\title{
Resumen
}

Esta investigación aborda el empoderamiento de las mujeres en el campo de Paraná que participan en cadenas de comercialización de alimentos cortos. El problema de la investigación pregunta: ¿las mujeres de la agricultura familiar se reconocen a sí mismas como agentes económicos productivos? El objetivo es analizar las percepciones de las mujeres vinculadas a la Asociación de Productores Comerciales de Guarapuava (APROFEG) sobre su empoderamiento socioeconómico y psicosocial y el papel de las políticas públicas locales en estos procesos sociales. Sobre la base de la crítica de la invisibilidad del trabajo doméstico y el cuidado realizado históricamente por las mujeres, la investigación busca entender cómo las mujeres en el campo se perciben dentro de la familia y el sistema de producción donde se insertan, y si pueden reconocer su trabajo como productivo y no sólo "ayudar" al cónyuge. La metodología tenía un carácter cualitativo-cuantitativo, realizada a partir de la aplicación de 9 (nueve) entrevistas estructuradas y 3 (tres) semiestructuradas sobre tres dimensiones estructurativas: socioeconómica, calidad de vida y dignidad, todas realizadas en el municipio de Guarapuava/PR, en 2019. También fueron entrevistados el Secretario Municipal de Agricultura y el Nutricionista de la secretaría. Los resultados muestran que las mujeres de este grupo se reconocen a sí mismas como agentes económicos productivos cuando se identifican como "agricultores" y que tienen un cierto grado de empoderamiento. La investigación identificó que las políticas públicas municipales, alineadas con los cambios institucionales, pueden ser mecanismos de emancipación de estas mujeres.

Palabras clave: Economía feminista; Desarrollo Rural y Regional; Agricultura Familiar; Circuitos Cortos. 


\section{INTRODUÇÃO}

A agricultura familiar é uma das estratégias de geração de renda e desenvolvimento rural e regional de muitas comunidades brasileiras, as quais têm características, formas de organização, meios de vida e produção próprios. Neste contexto, o trabalho das mulheres agricultoras é indispensável para manutenção da agricultura familiar e produção de alimentos saudáveis. Contudo, as mulheres rurais sofrem com a desigualdade de gênero, que é expressa pela invisibilidade do trabalho reprodutivo e a inferiorização de suas atividades produtivas, frequentemente caracterizadas como "ajuda" ao esposo (KEMPF; WEDIG, 2019).

As atividades desempenhadas pelas mulheres são organizadas pela divisão sexual do trabalho, uma "designação prioritária dos homens à esfera produtiva e das mulheres à esfera reprodutiva e, simultaneamente, a apropriação pelos homens das funções com maior valor social adicionado" (HIRATA; KERGOAT, 2007 p. 599). Dessa forma, as mulheres ficam responsáveis por atividades domésticas, de cuidados e de alimentação da família, considerados femininos e justificados por sua "natureza" maternal. Mesmo assim, as agricultoras participam de atividades produtivas, como o trabalho na lavoura, trato de animais e o processamento de alimentos, que servem tanto para autoconsumo quanto para venda (BONI, 2005; HEREDIA; CINTRÃO, 2006).

Apesar de sua menor participação em espaços públicos devido a dupla jornada de trabalho e sobreposição de tarefas, as mulheres participam ativamente na construção das cadeias curtas de abastecimento, principalmente através de vendas diretas e feiras. As cadeias curtas podem ser definidas como alternativas ao sistema alimentar hegemônico devido a sua sustentabilidade, oferta de alimentos de boa qualidade, por aumentar os ganhos das(os) agricultoras(es) e possibilitar a formação de relações de proximidade socioespacial com consumidoras(es). Dessa forma, a contribuição inovadora deste estudo é evidenciar o trabalho que as agricultoras desempenham em cadeias curtas de abastecimento no Município de Guarapuava, Região Centro-Oeste do Paraná (SUCUPIRA, 2016; GAZOLLA; SCHNEIDER, 2017; BELLETTI; MARESCOTTI, 2020; CABAÑAS; NIGH; POUZENC, 2020).

Diante destes apontamentos, a pesquisa questiona: as mulheres da agricultura familiar se reconhecem como agentes econômicas produtivas? A hipótese afirma que sim e admite que as políticas públicas locais são mecanismos de emancipação e independência financeira para as mulheres do campo. Já o objetivo do trabalho consiste em analisar as 
percepções das mulheres ligadas a Associação dos Produtores Feirantes de Guarapuava (APROFEG) sobre o seu empoderamento socioeconômico e psicossocial e o papel das políticas públicas locais nestes processos sociais.

Além desta seção introdutória e das considerações finais, o texto conta com uma seção de revisão teórica onde se apresentam as principais abordagens que embasam o estudo. Uma seção de metodologia onde se expõe as escolhas e caminhos metodológicos adotados na investigação e uma seção de descrição dos dados e análise dos resultados da pesquisa.

\section{AUTONOMIA FEMININA E A CONSTRUÇÃO SOCIAL DOS MERCADOS ALIMENTARES}

A agricultura brasileira se desenvolveu em um contexto de heterogeneidade, tendo de um lado agricultores vulneráveis e, de outro, médios e grandes produtores com maior acesso a mercados e mais fortalecidos para superar ciclos de adversidade, sendo historicamente apoiados pelas políticas públicas que ajudaram a fomentar desigualdades estruturais entre segmentos sociais (WANDERLEY, 2003).

$\mathrm{Na}$ agricultura familiar as mulheres participam principalmente de atividades na esfera privada e doméstica, de cuidados dos filhos ou idosos, cultivo de hortaliças e agroindustrialização de alimentos para autoconsumo, além do trato a pequenos animais. Apesar disso, elas não estão isentas de realizar atividades agrícolas, consideradas masculinas, criando uma dupla jornada de trabalho (HEREDIA; CINTRÃO, 2006). Dessa forma, é preciso considerar a desigualdade de gênero, visto que a qualidade de vida destas mulheres pode ser afetada devido ao acúmulo de tarefas alinhado a falta de infraestrutura do campo.

A qualidade de vida é considerada como a superação das privações de acesso e a satisfação das necessidades básicas humanas, o que requer um olhar atento ao social e suas carências. As necessidades básicas a ser contempladas são alimentação, expectativa de vida, boas condições de moradia, saúde, oportunidades de educação, entre outros aspectos. Olhar atentamente para a redução e solução destas privações é uma das maneiras de se efetivar a melhoria do bem-estar das mulheres agricultoras e suas famílias, garantindo sua dignidade e possibilidades de reprodução social (FURTADO, 1980; SEN, 2000).

Hirata e Kergoat (2007) comentam que às mulheres ficam condicionadas aos espaços domésticos e às atividades de subsistência, já aos homens cabem os espaços de 
trabalho produtivo, remunerado, fora da unidade domiciliar e de maior prestígio social. Raworth (2019) afirma que o trabalho desempenhado pelas mulheres é considerado reprodutivo, pois não produz valores monetários, sendo denominado de "segunda economia" ou "economia do cuidado". Este trabalho chamado de reprodutivo é inferiorizado diante do trabalho profissional, que é desempenhado historicamente pelos homens (BONI, 2005).

A desigualdade de tarefas para cada sexo é estrutural e intrinsecamente ligada à cultura histórica da sociedade. A desconstrução deste ideário pode ser feita com o auxílio do Estado via políticas públicas de gênero, as quais permitem mudanças estruturais junto aos atores sociais. Outra via de mudança é a transformação das instituições informais e formais que podem formar uma nova "mentalidade social" sobre a estrutura de gênero, a fim de desencadear um novo e diferente processo histórico evolutivo das sociedades, marcado até então, pela dicotomia dos papéis sociais de gênero (GEHLEN, 2004; NORTH, 1994).

Além disso é preciso levar em conta o formato de construção da identidade individual das mulheres, visto que "a mulher é fabricada por um longo trabalho psíquico" (VALDIVIA, 1997, p. 27). Segundo a teoria psicossocial de Erik Erikson (1902-1994) existem estágios de desenvolvimento da psique humana, bem como conflitos e crises ligadas, principalmente, a interação com o ambiente onde se vive. $\mathrm{O}$ enfoque psicossocial se baseia nas relações sociais que os indivíduos mantêm com a sociedade durante o desenvolvimento de sua psique e como estas influenciam seu comportamento e identidade. Durante o ciclo da vida, o ser humano desempenha papéis que são influenciados pelo meio social onde vive e, vice-versa, sendo assim sua psique co-construída historicamente (VERISSIMO, 2002).

Segundo a teoria psicossocial, a identidade das mulheres é afetada pela multiplicidade de papéis que são interpretados no decorrer do ciclo vital, por exemplo, o papel de filha, esposa e mãe. Estes papéis desempenhados com influência do ambiente social, moldam a visão de valor individual, conforme o nível de correspondência ao modelo apresentado. Mulheres que se consideram melhores mães e esposas, se sentem mais valorizadas ao "cumprir" com o papel "padrão" que é esperado do seu gênero (PAIVA, 2007; VERISSIMO, 2002).

Quando os papéis sociais ultrapassam os limites da qualidade de vida dos atores, começa a emergir a necessidade do empoderamento. Segundo Baquero (2012, p. 176), o empoderamento: "Diz respeito ao aumento da capacidade de os indivíduos se sentirem influentes nos processos que determinam suas vidas". O termo empowerment, muito usado 
por movimentos sociais do final da década de 1960, se refere, em nível individual, as habilidades que os indivíduos adquirem quando conseguem controlar as forças que agem sobre suas vidas, caminhando rumo a melhoria de sua situação social.

Bissoli e Thies (2020, p. 283) afirmam que o empoderamento é "instrumento para levar as mulheres ao desenvolvimento", visando melhorias em aspectos econômicos e individuais. Em termos coletivos, o empoderamento das mulheres visa uma mudança na estrutura social a fim de alcançar a igualdade entre homens e mulheres. Dessa forma, o empoderamento pode ser tanto individual, alcançado pelo aumento de renda e maior autonomia, quanto coletivo, alcançado por mudanças estruturais ou institucionais que promovam a igualdade entre mulheres e homens.

Tanto a existência de políticas públicas, como as ações que visam mudanças institucionais, são caminhos viáveis para a democratização dos espaços rurais e o empoderamento das mulheres. Neste sentido, uma das ações que promovem empoderamento é a participação das mulheres agricultoras em circuitos curtos de comercialização de alimentos. Uma destas ações foi identificada por Galdino et al. (2017), na Vila Rural Santa Clara/PR, onde as agricultoras criaram um mercado de proximidade pautado em relações de confiança, de forma que $54 \%$ de sua produção é vendida diretamente para a comunidade e clientes da cidade.

Entretanto, a maior participação das mulheres ainda é no processo de produção e agroindustrialização dos alimentos que são comercializados pelas cadeias curtas. As agricultoras que participam da venda direta geralmente trabalham nas feiras, enquanto os esposos fazem entregas ou negociações, pois muitas não possuem Carteira Nacional de Habilitação $(\mathrm{CNH})$. Ainda são os homens que dirigem os carros, compram insumos, têm contato com os bancos e administram a renda gerada pela família (BONI, 2005).

Aliado a isso, existe a questão da posse da terra (herança) e a participação financeira das mulheres nas unidades familiares, as quais geralmente estão em segundo plano. Neste ínterim, a insatisfação com os papéis sociais de gênero contribui fortemente para movimentos de emigração feminina em busca de melhores expectativas de vida nas cidades (BRUMER; PANDOLFO; CORADINI (2008). Conforme Wedig et al. (2021) a emigração é tanto física, quando as mulheres saem dos espaços rurais para residir fora da unidade, quanto simbólica, quando buscam rendas externas, se tornando mais independentes, mas ainda residem nas unidades. Estes fatos, sobretudo a saída física, refletem na masculinização e envelhecimento 
do campo, onde $81 \%$ da população é masculina e $80 \%$ das unidades tem um homem como responsável legal (IBGE, 2017).

Este cenário reafirma a importância das políticas públicas no âmbito da equalização de gênero no meio rural, políticas que já ofereceram conquistas às mulheres, como o direito à titularidade das terras (no II Plano Nacional da Reforma Agrária - PNRA) e assistência técnica (obrigatoriedade da ATER prestar 50\% da assistência técnica para mulheres). Além disso, a Previdência Rural garantiu sua aposentadoria e o PRONAF Mulher permitiu financiar projetos que possibilitem a elas maior autonomia e geração de renda (HORA, 2015; INSS, 2019).

Neste sentido, a existência e apoio à constituição de feiras são políticas públicas municipais importantes, pois além de garantir maiores ganhos às agricultoras, devido ao encurtamento dos elos das cadeias, também são espaços democráticos e de socialização. Aguiar et al. (2018) ressaltam a relevância das cadeias curtas, tanto no sentido de ofertar alimentos saudáveis e confiáveis, com qualidade local, quanto por se constituírem em uma via de diversificação e agregação de valor às famílias das agricultoras.

Além da comercialização, as feiras oferecem às agricultoras espaços de inclusão, troca de experiências, cultura e lazer. Segundo Sucupira (2016), nas feiras livres é comum a formação de rodas de conversa de mulheres, onde elas debatem sobre diversos assuntos e se organizam politicamente. Fernandez (2019), que investigou o grupo "Mulheres da Terra" (Viamão/RS), comenta que as agricultoras que participam de cadeias curtas, se orgulham por produzir comida de verdade, considerando as(os) consumidoras(es) como parceiras(os) que colaboram para a continuidade de suas atividades.

Portanto, as feiras possibilitam a formação de relações de proximidade e confiança entre agricultoras(es) e consumidoras(es), onde as agricultoras conquistam espaços de representação e sociabilidade. Esta forma de comercialização é a resposta de preocupações crescentes em relação aos impactos do sistema alimentar hegemônico, mas também se originam do protagonismo das agricultoras(es) e consumidoras(es), que visam estimular processos de desenvolvimento rural e regional com sustentabilidade ambiental, inclusão social e circulação de recursos econômicos nos locais e regiões (GAZOLLA; SCHNEIDER, 2017; BELLETTI; MARESCOTTI, 2020, CABAÑAS; NIGH; POUZENC, 2020). 


\section{PROCEDIMENTOS METODOLÓGICOS}

A pesquisa é de caráter misto, empregando métodos qualitativos e quantitativos. A análise estatística não probabilística foi utilizada para descrever numericamente os dados das entrevistas estruturadas. Já o método utilizado para análise das entrevistas semiestruturadas foi a análise do discurso, que consiste em compreender as construções ideológicas presentes no mesmo (RAUPP e BEUREN, 2006).

A entrevista estruturada foi formulada a partir de duas variáveis, sendo elas: a) socioeconômica: avaliando qual a relação das mulheres com os recursos econômicos; e b) qualidade de vida: avaliando a percepção das mulheres quanto sua qualidade de vida. A entrevista semiestruturada foi formulada a partir da variável de dignidade, que teve como objetivo ouvir a opinião das mulheres sobre a importância do trabalho que desempenham na esfera privada (produtivo e reprodutivo) e entender sua percepção de importância no agregado familiar. As entrevistas foram aplicadas durante as feiras do município, principalmente devido a maior facilidade de contato com as agricultoras.

A aplicação das entrevistas ocorreu conforme a receptividade das agricultoras, alinhada ao menor movimento de consumidoras(es), visto que a coleta de dados foi feita durante o horário das feiras. Assim, as agricultoras não foram selecionadas para participar do estudo, mas sim, se prontificaram a participar quando convidadas. Foram entrevistadas nove (9) agricultoras, sendo que todas responderam a entrevista estruturada, que era mais rápida e dinâmica, e três (3) das nove mulheres aceitaram responder a entrevista semiestruturada, que demandava mais tempo e atenção.

Foram selecionadas cinco (5) das oito (8) feiras para a aplicação das entrevistas. A pesquisa de campo ocorreu entre 10 a 20 de setembro de 2019, nas feiras: Paróquia Sant'Ana (3 entrevistas estruturadas); Paróquia Divino Espírito Santo (3 entrevistas estruturadas e 3 semiestruturadas); Paróquia Santa Cruz (1 entrevista estruturada); Paróquia São João Bosco (2 entrevistas estruturadas); Espaço Cidadão da Primavera (não havia agricultoras), cujas características estão descritas no Quadro 1. 
Quadro 1. Informações sobre as experiências das feiras investigadas.

\begin{tabular}{|l|c|c|c|c|c|}
\hline \multicolumn{1}{|c|}{ Feiras } & Estandes & Rural & Urbano & Alimentos e produtos & $\begin{array}{c}\text { Agricultoras } \\
\text { na venda }\end{array}$ \\
\hline Vila Bela & 13 & 6 & 7 & $\begin{array}{c}\text { Hortaliças, frutas, verduras, doces, queijos, } \\
\text { embutidos, panificados e artesanato. }\end{array}$ & 4 \\
\hline Vila Carli & 16 & 5 & 11 & $\begin{array}{c}\text { Hortaliças, frutas, verduras, mel, queijo, doces } \\
\text { e geleias, panificados, lanches e artesanato. }\end{array}$ & 2 \\
\hline Primavera & 8 & 2 & 6 & $\begin{array}{c}\text { Hortaliças, panificados, bolachas, doces, } \\
\text { geleias, lanches e artesanato. }\end{array}$ & 0 \\
\hline Sant'Ana & 28 & 12 & 16 & $\begin{array}{c}\text { Hortaliças, frutas, verduras, mel, queijo, } \\
\text { doces, panificados, lanches, bebidas e } \\
\text { artesanato. }\end{array}$ & 7 \\
\hline $\begin{array}{l}\text { Santa } \\
\text { Cruz }\end{array}$ & 12 & 3 & 9 & $\begin{array}{c}\text { Hortaliças, verduras, lanches, doces, } \\
\text { panificados, geleias, bebidas e artesanato. }\end{array}$ & 1 \\
\hline
\end{tabular}

Fonte: Pesquisa de campo (2019).

Além deste levantamento junto as agricultoras feirantes, foram conduzidas duas entrevistas, uma com a Nutricionista responsável pela coordenação das agroindústrias comunitárias e, outra, com o Secretário de Agricultura, buscando compreender o funcionamento das políticas públicas locais e rurais que apoiam as mulheres.

As feiras do produtor rural fazem parte do Programa Vida Rural promovido pela Secretaria de Agricultura, desde 2013. Atualmente a feira é dirigida pela Associação dos Produtores Feirantes de Guarapuava (APROFEG) em parceria com a Secretaria de Agricultura. A mesma é aberta as famílias agricultoras, artesãs(aõs) e pequenas(os) empreendedoras(os) urbanas(os). O espaço é destinado à comercialização de alimentos in natura, de agroindústrias e minimamente processados, além da venda de lanches, bebidas e artesanatos. A participação é gratuita, sendo cadastrado como membro da associação.

Em relação ao local de investigação, o Município de Guarapuava está localizado na Região Centro-Sul do Estado do Paraná, possuindo área total de 3.177,598 km² e distante a $252,7 \mathrm{~km}$ da capital. Os dados de renda evidenciam que a mesma é concentrada no município, cujo índice de Gini é de 0,555, mais concentrado que o índice paranaense de 0,390, apesar de seu alto índice de desenvolvimento humano (0,731), alinhado com o do estado do Paraná de 0,749 e do Brasil 0,759 (IPARDES, 2021).

A população urbana estimada é de 152.993 mil habitantes (78.720 são mulheres) e no meio rural, estima-se população de 14.335 mil habitantes, sendo 6.811 mulheres. O rural conta ainda com 2.134 estabelecimentos agropecuários distribuídos em 207.561 mil hectares e tem 8.598 pessoas ocupadas. Dados do IPARDES (2021), para a safra de 2019, apontam que o destaque na produção agrícola fica por conta da soja e do milho com 280.416 e 170.520 
toneladas, respectivamente. Entre as lavouras temporárias, se destacam a produção de batata, trigo e, em menor proporção, a produção diversificada de frutas, hortaliças e vegetais.

\section{PERCEPÇÕES SOCIOECONÔMICAS E PSICOSSOCIAIS DAS MULHERES AGRICULTORAS NOS MERCADOS ALIMENTARES}

Esta seção trata dos dados primários da pesquisa realizada com as agricultoras do município através da entrevista estruturada de percepção aplicada. A primeira seção trata da percepção socioeconômica, a segunda seção trata da qualidade de vida e a terceira seção trata da dimensão de dignidade. Por fim, os discursos das agricultoras (entrevista semiestruturada) serão analisados e relacionados com o reflexo das políticas públicas na divisão sexual do trabalho e na autopercepção das mulheres como agricultoras.

\section{PERCEPÇÃo SOCIOECONÔMICA EM TERMOS DA EMANCIPAÇÃO FINANCEIRA}

Em relação aos aspectos financeiros, as questões versaram sobre a responsabilidade na gestão de renda, divisão do trabalho e documentos. Sobre a faixa de renda, cinco $(55,6 \%)$ das nove mulheres responderam que a família tem renda entre $\mathrm{R} \$ 500,00$ a $\mathrm{R} \$ 1.000,00$ reais, em média um salário mínimo ( $\mathrm{R}$ \$998,00, na data da pesquisa). Duas $(22,2 \%)$ entrevistadas afirmaram que a faixa de renda era entre $\mathrm{R} \$ 1.000,01$ até $\mathrm{R} \$ 1.500,00$, uma $(11,1 \%)$ indicou renda entre $R \$ 1.500,01$ e $R \$ 2.000,00$ e uma $(11,1 \%)$ respondeu que a renda da família é superior a $\mathrm{R} \$ 4.000,00$.

Apesar da renda ter forte relação com o trabalho, nenhuma das entrevistadas soube precisar quantos dias são trabalhados por ano pela família, fato decorrente da exigência de dedicação integral na agricultura ou, como elas definem, “de sol a sol”. Uma carga de trabalho que gera um salário mínimo para núcleos familiares compostos por pelo menos dois adultos e duas crianças, em média. A maior renda observada vem de uma família que os dois adultos possuem ensino superior e a mulher também é professora. Este resultado já havia sido evidenciado em outras pesquisas, por exemplo, em Schneider (2003), que conclui que famílias pluriativas conseguem auferir maiores rendas.

A iniciativa da Prefeitura e da Secretaria de Agricultura com a criação do Programa Vida Rural teve como objetivo aumentar a renda e a diversificação das famílias. Entretanto, para além da geração de renda é preciso verificar se as mulheres participam propriamente de 
gestão das finanças. Nos casos estudados, a responsabilidade de gestão da renda do domicílio fica partilhada entre homens e mulheres, onde em cinco dos nove casos, as mulheres afirmaram existir gestão compartilhada, em dois casos elas são as responsáveis e em outros dois casos, fica a cargo do marido.

Este cenário se inverte quando o foco são os afazeres domésticos. A responsabilidade dos afazeres domésticos é quase exclusiva das mulheres (6 casos), em apenas 3 casos ocorre a divisão com o marido, filhas ou com a família, mas, em nenhum caso, a responsabilidade é exclusiva do homem. Dados que refletem as afirmações teóricas encontradas em Hirata e Kergoat (2007) e Heredia e Cintrão (2006) que ressaltam para uma agricultura familiar, marcada pela divisão sexual do trabalho, com mulheres assumindo as tarefas domésticas e os cuidados da casa (atividades reprodutivas e sem ganhos monetários), mas também, assumem trabalhos agrícolas e de comercialização, o que caracteriza dupla jornada.

A maioria das mulheres entrevistadas afirmaram que a divisão sexual do trabalho é "normal e benéfica", entretanto, este panorama começa a apresentar mudanças, pois foi constatado que em alguns casos ocorre a divisão das tarefas. Apesar disso, nota-se a perpetuação dos papéis sociais de gênero, quando uma das entrevistadas admite que estes afazeres foram repassados para as duas filhas, demostrando ainda a relação do trabalho doméstico como atividade puramente feminina, como afirmado por Hirata e Kergoat (2007) e Piscitelli (2009).

Sobre o registro da geração da renda, em cinco casos o registro é feito via Nota Fiscal do Produtor, no entanto, elas participam como associadas visto que o representante oficial no documento fiscal é o marido. Somente um caso tem a mulher como representante oficial no documento. Além disso, em outros 3 casos, ou não se tem comprovante de renda ou é feito via Carteira de Trabalho e Previdência Social (CTPS) ou pelo sindicato rural.

No quesito profissão, $100 \%$ das respondentes se declararam agricultoras, sendo que uma delas também se declarou professora e outra hortifrutigranjeira. $\mathrm{O}$ reconhecimento de agricultora que deve ir além do seu status social, pois envolve o acesso à direitos civis como aposentadoria. Segundo Heredia e Cintrão (2006), este autorreconhecimento como agentes econômicas produtivas na sociedade é importante para as mulheres, pois demonstra que elas participam dos espaços sociais e são reconhecidas.

O fato de encontrar mulheres com outras profissões (professora) remete à afirmação de Brumer, Pandolfo e Coradini (2008), de que as mulheres estão optando por outras 
profissões fora do campo, buscando reconhecimento, visibilidade de seu trabalho, melhores oportunidades e rendas externas. Segundo Wedig et al. (2021), estas buscas se apoiam em movimentos de saída física e simbólica do campo e isto fica evidente nos dados de proporção de homens e mulheres residindo na agricultura.

De acordo com o IPARDES (2021), no Município de Guarapuava, a população rural feminina é de 6.811 mil contra 7.524 mil homens. O Censo Agropecuário 2017 apronta que no Brasil $81 \%$ da população rural é formada por homens e a maioria destes têm entre 45 e 54 anos. Estes dados podem ser explicados pelas dificuldades e marginalização que as mulheres (especialmente jovens) passam no rural e pela exclusão dos processos de partilha da herança.

A falta de acesso a documentos, como a Carteira Nacional de Habilitação (CNH), também gera entraves aos processos reprodutivos das mulheres rurais, visto que a facilidade de locomoção permite diversificar suas estratégias de renda junto aos mercados, sem depender de seus maridos e filhos. Diante disso, a pesquisa questionou se as agricultoras possuíam carteira de habilitação e constatou que apenas 3 delas $(33,3 \%)$ possuem a $\mathrm{CNH}$, as demais (66,7\% dos casos) afirmaram não possuir $\mathrm{CNH}$, o que confirma o exposto por Boni (2005) sobre o menor acesso ao documento pelas mulheres.

Outros fatores que bloqueiam o acesso a $\mathrm{CNH}$ são o baixo poder aquisitivo e escolaridade. Neste sentido, o município poderia facilitar o acesso das agricultoras através de políticas públicas que promovam auxílio financeiro para conquista do documento. $\mathrm{Na}$ percepção do Secretário de Agricultura e da Nutricionista do Programa Vida Rural, a falta de acesso a CNH é um fator limitante para a atividade econômica das mulheres, visto que muitas demonstram vontade de acessar mercados nos espaços urbanos, mas dependem dos companheiros para o transporte. Isso demonstra o exposto por Kempf e Wedig (2019) quando afirmam que às mulheres ficam reservados espaços na esfera privada.

As mulheres foram arguidas sobre o acesso ao sistema financeiro e conta bancária, para verificar suas liberdades financeiras. Em 55,5\% dos casos a conta bancária é conjunta com o marido e, em um dos casos, a mulher não usa serviços bancários. Em 33,3\% dos casos, as mulheres declararam ter conta corrente e poupança individuais, estas coincidem com maiores níveis de escolaridade. Em relação aos empréstimos, 77,8\% afirmaram não possuir, enquanto 22,2\% possuem crédito do PRONAF, mas em nome do marido, demonstrando que a política pública do PRONAF Mulher ainda não alcançou as agricultoras do município. 
Foi levantado na entrevista a possibilidade das mulheres se manterem financeiramente sem o companheiro, sendo que cinco das nove mulheres entrevistadas afirmaram que não conseguiriam ter renda suficiente para cuidar de si e dos filhos. As iniciativas públicas como a feira do produtor, se mostram importantes, pois constroem processos de independência financeira através da comercialização por cadeias curtas. Alinhado a isso, o município poderia promover cursos de educação financeira, dotando-as de conhecimentos que na falta do esposo (separação ou falecimento) seriam fundamentais.

Em termos de emancipação financeira, apesar de todas afirmarem que a gestão da renda do domicílio é compartilhada, fatores como o menor acesso ao sistema financeiro, falta da $\mathrm{CNH}$ e da Nota de Produtora Rural, limitam a emancipação financeira das mulheres. Apesar da identificação destas limitações de gênero, as entrevistadas se reconhecem como agentes econômicas produtivas e se denominam agricultoras, mesmo exercendo também atividades domésticas, o que reafirma o exposto por Heredia e Cintrão (2006), sobre a dupla jornada das mulheres do campo.

\section{PERCEPÇÃO SOCIOECONÔMICA EM TERMOS DA QUALIDADE DE VIDA}

Este trabalho entende a qualidade de vida a partir dos estudos de Furtado (1980) e Sen (2000) como acesso a direitos fundamentais: educação, autonomia, saúde e meios para uma vida digna, que são necessários para a expansão das liberdades e capacidades humanas. Nesta variável as mulheres responderam questões sobre idade, saúde, condições de moradia e composição familiar. O objetivo destas questões é avaliar como as políticas públicas apoiam as agricultoras. As mulheres apresentaram idades entre 30 a 50 anos e baixa escolaridade (três tinham apenas o ensino fundamental, três o ensino fundamental incompleto, duas o ensino médio completo e uma o ensino superior completo).

De acordo com o PNUD, IPEA e FJP (2017) a taxa de analfabetismo rural é de 11,5\% (mais que o dobro da taxa de analfabetismo urbana), sendo que a população rural que frequenta o ensino superior é de apenas $2,4 \%$, enquanto no meio urbano é $14,5 \%$. A escolaridade pode incrementar as estratégias de sobrevivência das famílias, uma vez que o capital humano abre maiores oportunidades de renda, compreensão de realidade, proposição de soluções para problemas, construção de mercados e inserção em novas atividades agrícolas e não agrícolas nos espaços rurais. 
A pesquisa também levantou a distância das residências as escolas, admitindo que a maior proximidade contribui para a redução da taxa de analfabetismo entre a população do campo, principalmente entre as mulheres. Foi verificado que as escolas estão no raio de 10 a $20 \mathrm{~km}$ das residências, concentradas no perímetro urbano. Vale pontuar que a educação de jovens e adultos é de responsabilidade do município que recebe repasses do Fundo de Participação dos Municípios (FPM) e Fundo de Manutenção e Desenvolvimento da Educação Básica e de Valorização dos Profissionais da Educação (FUNDEB) (MINISTÉRIO DA FAZENDA, 2019).

Apesar de Guarapuava contar desde 2015 com o Plano Municipal de Educação (PME), cuja meta é atingir um mínimo de 12 anos de escolaridade entre a população rural, além de erradicar o analfabetismo, não está ocorrendo oferta de Ensino de Jovens e Adultos em escolas rurais. Aliado a isso, a faixa etária de foco do PME está abaixo da média de idade das respondentes da pesquisa, o que evidencia a necessidade de ampliação da política pública visando atender mulheres de faixas etárias mais elevadas que almejam concluir os estudos (GUARAPUAVA, 2015).

Quando questionadas sobre quem seria o "chefe da família" (no sentido de gestão e tomada de decisões), os dados indicam que 55,6\% das unidades familiares é dirigida em conjunto por ela e seu esposo. Três delas afirmaram que o esposo é o chefe e uma delas disse que era a própria chefe da família, dados que complementam as respostas sobre quem administra a renda, onde também cinco das nove mulheres faziam gestão da renda compartilhada. As duas questões demonstram que existe um processo de mudanças no sistema decisional, com tendência a igualdade de gênero.

Apesar disso, as mulheres geralmente decidem sobre assuntos domésticos, o que confirma o exposto por Boni (2005 p. 52) que sobre a alocação dos recursos produtivos geralmente "quem determina a divisão de funções é o homem". A falta de participação nas decisões financeiras da família pode tornar mais difícil um cenário onde as mulheres precisem manter a si e seus filhos sem a presença do esposo (caso de separação ou falecimento).

Em termos da saúde e de acesso às Unidades Básicas de Saúde (UBS), mesmo existindo uma política pública que é o programa de UBSs rurais do Governo Federal, notouse que as distâncias das UBSs das residências das entrevistadas variam entre 10 e $20 \mathrm{~km}$. Em Guarapuava, de acordo com o Cadastro Nacional de Estabelecimento de Saúde (CNES), das 
32 UBSs somente 6 estão em distritos e não são classificadas como UBS Rural, mas sim de Estratégia de Saúde da Família (ESF), com equipes móveis que se deslocam para atendimento, diferente da UBS que possuem equipe fixa (DATASUS, 2019).

Apesar dos entraves ao acesso à saúde e educação, quando questionadas sobre sua qualidade de vida, seis $(66,7 \%)$ entrevistadas classificaram como boa; duas $(22,2 \%)$ entenderam como muito boa e uma $(11,1 \%)$ como nem boa, nem ruim. Sobre a sua saúde seis das nove mulheres disseram estar muito satisfeitas; duas afirmaram não estar satisfeitas e uma disse estar muito insatisfeita, o que demonstra a necessidade de aperfeiçoar as estratégias de saúde para as agricultoras. As UBS também são a primeira linha de defesa contra a violência doméstica, sendo importantes para garantir segurança e qualidade de vida.

Além disso, existe a importância da discussão sobre o sentimento de pertencimento destas mulheres, pois o lugar onde se vive diz muito sobre seu modo de pensar, seus hábitos, comportamentos, identidades, objetivos e sua percepção de si mesmas. As percepções em torno da variável da qualidade de vida apontam para uma condição boa, apesar das dificuldades encontrados pela pesquisa que poderiam ser resolvidos com o aperfeiçoamento das políticas públicas já existentes para as mulheres. Mesmo diante destes fatores limitantes, as mulheres entrevistadas demonstraram estar satisfeitas em viver no ambiente em que estão inseridas.

\section{PERCEPÇÃo PSICOSSOCIAL EM TERMOS DA DIGNIDADE}

Esta subseção discute e analisa a percepção psicossocial das mulheres em termos de dignidade, pela perspectiva de valor que as mulheres atribuem a suas atividades diárias. A variável levantou a percepção pessoal das mulheres sobre a importância e o valor que elas mesmas atribuem ao seu trabalho; trabalho que por vezes é rotulado como invisível, gratuito, marcado pela divisão sexual e por não estar ligado a geração de renda. Quando inserido no espaço público (trabalho produtivo e remunerado) sofre com a desigualdade salarial se comparado a remuneração recebida pelos homens nas mesmas funções (PISCITELLI, 2009; HIRATA; KERGOAT, 2007).

Himanen (2014) afirma que a noção de dignidade e de valor próprio levaria a sociedade a um novo nível de desenvolvimento, substituindo lucros e valores monetários pela valorização humana. Para o autor, uma vida digna, vai além de satisfazer as necessidades 
básicas dos indivíduos, implica acesso à cultura, liberdades em todas as esferas, economia e meio ambiente sustentáveis e bem-estar social. Quando o bem-estar se torna o objetivo da economia, ao invés da riqueza (PIB), este deslocamento promove fatores que contribuem para o desenvolvimento humano e dignidade, além de estimular processos de empoderamento e aumento das capacidades dos indivíduos (SEN, 2000).

A maioria $(66,7 \%)$ das agricultoras afirmou se considerar alguém de muito valor e três $(33,3 \%)$ se consideram alguém de valor. Segundo Piscitelli (2009), Hirata e Kergoat (2007) esta visibilidade (valor ou reconhecimento pessoal) é desenvolvido a partir do seu trabalho ser reconhecido no contexto em que vivem, sem rótulos de inferioridade de gênero. Para as mulheres do campo, ter noção de sua dignidade é importante no sentido de não aceitar opressões e imposições inerentes ao sistema de poder hegemônico, principalmente aquelas que desvalorizam seu trabalho e papéis sociais.

Nota-se a necessidade de entendimento do valor pessoal para que este aspecto possa ser institucionalizado e interiorizado na cultura humana, a fim de mudar paradigmas econômicos e sociais. Durante a entrevista, as mulheres foram questionadas sobre o valor da mulher na família e nas atividades que desenvolvem na vida privada. Para a Entrevistada 1 a mulher é tudo na família, pois:

\section{se não tiver uma mulher na família desanda tudo, ela dá a estrutura da casa. Se uma mulher for meio acomodada, desanda tudo, agora se ela for agitada ela ajuda o marido, ajuda o pai, ajuda a mãe a dar uma organizada, a responsabilidade da casa é da mulher (ENTREVISTA 1: Agricultora, Guarapuava/PR, setembro de 2019).}

A Entrevistada 1 não tem filhos, mas cuida dos pais idosos, além de realizar o trabalho doméstico e o trabalho na agricultura. Ela afirmou ainda que o trabalho doméstico desempenhado é muito valorizado pelo esposo, mas não pelo seu pai, que entende que ela apenas cumpre sua obrigação de mulher. Este entendimento de seu pai idoso demonstra o que Verissimo (2002) e Paiva (2007) discutem acerca da formação psicossocial das mulheres, que é predominantemente orientada para tarefas de cuidados. Além disso, a Entrevistada 1 entende que a responsabilidade das tarefas domésticas é das mulheres, demonstrando o que Hirata e Kergoat (2007), Kempf e Wedig (2019) e Boni (2005) afirmam em seus estudos.

Já para a Entrevistada 2, a mulher tem muito valor dentro da família, sendo responsável pela estrutura do lar. E para a Entrevistada 3, o papel da mulher é essencial, não existindo lar sem a mulher, na sua percepção: "não existe um lar sem uma mulher ali dentro, 
não só pelo serviço que ela faz, mas pela presença dela mesmo" (ENTREVISTA 3: Agricultora, Guarapuava/PR, setembro de 2019). A fala das agricultoras refletem que a formação psicossocial das mulheres, tanto no meio urbano quanto rural, é orientada por características biológicas que determinam os papéis sociais de gênero. Nesse sentido, quando elas afirmam que a presença da mulher forma um lar refere-se às qualidades "inatas" de cuidado, amor e afeto que são atribuídas as mulheres, como evidenciado por Paiva (2007) e Valdivia (1997) sobre a formação psicossocial das mulheres.

As mulheres também foram inquiridas sobre o valor que lhes é atribuído em suas atividades pela sociedade quando comparadas ao valor dado as atividades dos homens. Para a Entrevistada 1 as mulheres são desvalorizadas em relação aos homens diante da sociedade e afirmou que isso se reflete nos salários, pois geralmente as mulheres ganham menos para desempenhar as mesmas funções. Segundo ela: "os homens são mais valorizados desde o salário que o homem ganha, a mulher pode fazer o mesmo serviço e ganha bem menos" (Entrevista 1: Agricultora, Guarapuava/PR, setembro de 2019). É o que indica também o IBGE (2018), tendo em vista que o salário médio da mulher na agricultura de $\mathrm{R} \$ 882,00$, contra R \$ 1.373,00 dos homens.

Esta fala reflete a análise de Boni (2005) sobre como o trabalho das mulheres é inferiorizado e menos remunerado por ser considerado "leve". A Entrevistada 1 também afirmou que na feira o tratamento e as oportunidades são iguais, dizendo: "aqui na feirinha não é assim, aqui eles tratam nós iguais”. Uma afirmação importante, pois, demonstra que esta política pública de cadeia curta construída no município tem auxiliado na promoção da equidade entre os sexos, bem como, no empoderamento feminino. Sucupira (2016) ressalta a importância da organização das feiras colocar como regra a participação da família, para que as mulheres e meninas sejam incluídas nestes espaços de socialização e comercialização.

De maneira semelhante, as Entrevistadas 2 e 3 também acreditam que a sociedade valoriza menos as funções desempenhadas pelas mulheres em relação as masculinas. No caso da Entrevistada 2, sua resposta foi bastante rápida e acompanhada de uma expressão de desânimo, evidenciando que ela já havia refletido antes sobre o assunto. Esta percepção da valorização do trabalho masculino na sociedade, alinhada ao menor acesso à terra, crédito e mercados pode levar a processos de vulnerabilização e emigração feminina como exposto por Brumer, Pandolfo e Coradini (2008) e Wedig et al. (2021). 
Ainda sobre a remuneração do trabalho doméstico, elas foram questionadas sobre quanto vale o trabalho doméstico em termos monetários e, se fosse remunerado, quanto deveria ser pago por ele. Para a Entrevistada 1 o valor deveria ser superior a um salário mínimo, já a Entrevistada 2 considera como justo dois salários mínimos devido a continuidade das tarefas. A capacidade de avaliar quanto vale o seu salário, baseado principalmente na "continuidade das tarefas" pode auxiliar na transição das instituições informais, que consideram estas atividades como trabalho "leve".

Na percepção da Entrevistada 3 o trabalho que desempenha dentro da casa não tem preço, ela afirma que "não tem dinheiro que pague no mundo a função de uma mulher dentro de casa, não tem valor porque é uma coisa que eu faço por amor". Novamente fica evidenciado na fala da entrevistada que a formação psicossocial dos papéis desempenhados pelas mulheres nos agregados familiares ainda tem bases biológicas e deterministas, colocando o amor no centro como remuneração máxima pelas suas horas trabalhadas, como demonstrado por Heredia e Cintrão (2006), Hirata e Kergoat (2007); Bumer, Pandolfo e Coradini (2008) e Piscitelli (2009).

Dessa forma, a construção de cadeias curtas de abastecimento que incluam as agricultoras é de suma importância para seus processos de empoderamento, pois até mesmo para as mulheres é difícil enxergar o trabalho doméstico como produtivo. Segundo Sucupira (2016), mesmo diante da invisibilidade do trabalho doméstico e de cuidados as agricultoras constroem sua autonomia através das cadeias curtas alimentares, assim como evidenciado por Galdino et al. (2017), quando contam a trajetória de redesenho dos mercados agroalimentares locais promovido pelas mulheres.

O incentivo da participação das mulheres nas cadeias curtas é importante principalmente em um cenário em que afirmam que não seriam capazes de manter a si e a seus filhos sem seus esposos. Fernandez (2019) demonstra que a participação das mulheres nas cadeias curtas é capaz de transformar os papéis sociais de gênero, uma vez que as decisões de gestão e a distribuição do trabalho doméstico e de cuidados se tornam mais igualitárias, garantindo às agricultoras maior autonomia e independência financeira.

Ademais, as respostas das agricultoras entrevistadas demonstram que este grupo tem consciência da importância das atividades que desempenham no dia a dia no agregado familiar e tem noção da desvalorização social do trabalho doméstico e de cuidados. Uma das mulheres entrevistadas revelou um traço marcante das mulheres (sejam do campo ou da 
cidade) que reafirmam o exposto pelo referencial teórico do trabalho: as mulheres aceitam determinados papéis e atividades em nome do carinho, do cuidado materno e do amor.

\section{CONSIDERAÇÕES FINAIS}

O objetivo do trabalho consistiu em analisar as percepções das mulheres ligadas a Associação dos Produtores Feirantes de Guarapuava (APROFEG) sobre o seu empoderamento socioeconômico e psicossocial e o papel das políticas públicas locais nestes processos sociais. A hipótese de que as políticas públicas se apresentam como mecanismos de emancipação e independência financeira para a mulher do campo, promovendo a qualidade de vida das mulheres rurais é verdadeira, pois a partir dos dados levantados notouse que as políticas públicas do município oferecem certo grau de empoderamento feminino.

Em relação a variável socioeconômica, a pesquisa evidenciou que as mulheres têm ganhado maior espaço de participação nas decisões financeiras e se identificam como agricultoras, mas que ainda há casos em que a gestão da renda é centralizada no esposo. No caso da variável de qualidade de vida, conclui-se que as mulheres têm pouco acesso à educação e saúde e que não há políticas públicas focadas na resolução destes problemas. Já em relação a variável dignidade, a investigação mostrou que as mulheres se identificam como pessoas de valor, mas ainda seguem a estrutura patriarcal de divisão sexual do trabalho, além de desempenhar papéis sociais pelo amor a família.

Percebe-se a necessidade de políticas direcionadas efetivamente às mulheres e não apenas para o núcleo familiar, pois não há nenhuma delas focalizada em potencializar processos de empoderamento. A associação e a Prefeitura local podem atuar em conjunto para o fortalecimento de experiências de sucesso, como as relatadas por Sucupira (2016) e Galdino et al. (2017), em que há processos de empoderamento em cadeias curtas de abastecimento de alimentos.

Ademais, as mulheres têm presentes as opressões que sofrem diante da sociedade e dentro da própria família, mas esta institucionalidade informal pode ser expandida, não para fragilizar as famílias rurais, seus repertórios culturais e meios de vida, mas para promover a equidade de tarefas (principalmente no âmbito de atividades domésticas) e a inserção das mulheres na gestão financeira do núcleo familiar e comercialização de seus alimentos. 


\section{REFERÊNCIAS}

AGUIAR, L. C.; DELGROSSI, M. E.; THOME, K. M. Short food supply chain: characteristics of a family farm. Ciência Rural, Santa Maria, v. 48, n. 5, e20170775, 2018.

BAQUERO, Rute Vivian Angelo. Empoderamento: instrumento de emancipação social uma discussão conceitual. Revista Debates, Porto Alegre, v. 6, n. 1, p. 173-187, 2012.

\section{BELLETTI, G.; MARESCOTTI, A. Short food supply chains for promoting local food} on local markets: inclusive and sustainable industrial development. FAO, 2020. 52 p.

BISSOLI, M. W. L.; THIES, V. F. Empoderamento feminino e sociobiodiversidade do Cerrado brasileiro: o caso das mulheres agricultoras de Anastácio -MS. In: PREISS, Potira V.; SCHNEIDER, Sergio (org.). Sistemas alimentares no século XXI: debates contemporâneos. Porto Alegre: Editora Ufrgs, 2020. Cap. 2020. p. 279-289.

BONI, Valdete. Produtivo ou reprodutivo: o trabalho das mulheres nas agroindústrias familiares - um estudo na região oeste de Santa Catarina. 2005. 99 f. Dissertação (Mestrado em Sociologia Política) - Universidade Federal de Santa Catarina, Florianópolis, 2005.

BRASIL. Diário Oficial da União. Decreto $\mathbf{n}^{\mathbf{0}} \mathbf{9 . 6 6 1}$ de $\mathbf{1}^{\circ}$ de janeiro de 2019. Disponível em: 〈 D9661 (planalto.gov.br) > Acesso em 10 de outubro de 2019.

BRUMER, A.; PANDOLFO, G. C.; CORADINI, L. Gênero e agricultura familiar: projetos de jovens filhos de agricultores familiares na Região Sul do Brasil. In: Seminário

Internacional Fazendo Gênero 8: Corpo, Violência e Poder, 25 a 28 de agosto de 2008. Florianópolis/SC.

CABAÑAS, A. A. G.; NIGH, R.; POUZENC, M. (org.). La comida de aquí: retos y realidades de los circuitos cortos de comercialización. México: Centro de Investigaciones Multidisciplinarias sobre Chiapas y la Frontera Sur, Universidad Nacional Autónoma de México, 2020. 279 p.

DATASUS. Cadastro Nacional de Estabelecimento de Saúde: Unidade Básica de Saúde em Guarapuava, 2019. Disponível em:

$<$ http://cnes2.datasus.gov.br/Mod_Ind_Unidade_Listar_Novo.asp?VTipo=001\&VListar=1

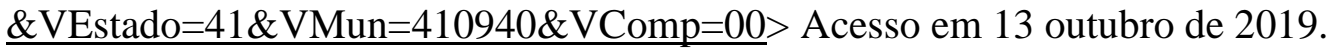

FERNANDEZ, Sarita Mercedes. Estratégias de reprodução social na agricultura familiar: o caso do grupo mulheres da terra - Viamão/RS. 2019. 232 f. Tese (Doutorado) - Curso de Pós-Graduação em Desenvolvimento Rural, Faculdade de Ciências Econômicas da UFRGS, Porto Alegre, 2019. Cap. 4.

FURTADO, C. Pequena introdução ao desenvolvimento: enfoque interdisciplinar. São Paulo: Ed. Nacional, 1980.

GALDINO, I.; SOUZA, F.; ALVES, A.; FEIDEN, A.; VORPAGEL, J. Os circuitos curtos de comercialização dos produtos agroecológicos das mulheres da vila rural santa clara. In: 
SEMINÁRIO INTERNACIONAL DE PÓS-GRADUAÇÃO EM DESENVOLVIMENTO RURAL SUSTENTÁVEL, 1., 2017, Marechal Cândido Rondon. Anais [...]. Marechal Cândido Rondon: Unioeste, 2017. p. 1-15.

GAZOLLA, M.; SCHNEIDER, S. Cadeias curtas e redes agroalimentares alternativas: negócios e mercados da agricultura familiar. Porto Alegre: UFRGS, 2017. 520 p. (Estudos Rurais).

GEHLEN, I. Políticas públicas e desenvolvimento social rural. São Paulo em perspectiva, São Paulo/SP, v. 18, n. 2, 2004 p. 95-103.

GUARAPUAVA - Boletim Oficial do Município. Lei no 2.414 de 16 de junho de 2015. Disponível em: 〈https://bit.ly/3dzdhL0> Acesso em 27 de março de 2020.

HEREDIA, B. M. A.; CINTRÃO, R. P. Gênero e acesso a políticas públicas no meio rural brasileiro. Revista Nera, Presidente Prudente/SP, n. 8, jan/jun de 2006, p. 1-28.

HIMANEN, P. Dignity as development. In: CASTELLES, Manuel; HIMANEN Pekka. Reconceptualizing development in the global information age, Oxford Scholarship Online p. 287-325. Oxford - UK, 2014.

HIRATA, H.; KERGOAT, D. Novas configurações da divisão sexual do trabalho. Cadernos de pesquisa, São Paulo, v. 37, n. 132, dezembro de 2007, p. 595-609.

HORA, K. Políticas Públicas para Mulheres Rurais. Brasília: Mimeo, 2015.

IBGE. Censo Agropecuário de 2017. Site: IBGE | Censo Agro 2017 | Home. Acesso em 15 nov. de 2020.

IBGE - Instituto Brasileiro de Geografia e Estatística. Pesquisa Nacional por Amostra de Domicílios Contínua: divulgação especial, mulheres no mercado de trabalho, 2018. Disponível em: <IBGE | Biblioteca $\mid$ Detalhes |Pesquisa Nacional por Amostra de Domicílios Contínua : divulgação especial : mulheres no mercado de trabalho $>$ Acesso em: 09 ago. 2019.

INSS - Instituto Nacional do Seguro Social. Documentos - trabalhador rural. Disponível em: <Documentos - Trabalhador rural — Português (Brasil) (www.gov.br) >Acesso em 22 de agosto de 2019.

IPARDES - Instituto Paranaense de Desenvolvimento Econômico e Social. Caderno Estatístico Município de Guarapuava. 2021. Disponível em: < MontaCadPdf1.php (ipardes.gov.br)> Acesso em 27 de fev. de 2021.

KEMPF, R. B.; WEDIG, J. C. Processos de resistência de mulheres camponesas: olhares pela perspectiva decolonial. Mundo Agrario: Revista de estudios rurales, Buenos Aires, v. $20, \mathrm{n}^{\mathrm{o}} 43,2019$. 
MINISTÉRIO DA FAZENDA. Secretaria do Tesouro Nacional. Manual de Contabilidade Aplicada ao Setor Público. $8^{\text {a }}$. ed. Brasília, 2019. Disponível em: < $\underline{\text { Manual }}$ de Contabilidade Aplicada ao Setor Público (MCASP) - 2019 - Tesouro Transparente> Acesso em 03 agos. de 2019.

NORTH, D. C. Economic Performance Through Time. The American Economic Review, v. 84, n. 3, p. 359-368, 1994.

PAIVA, G. J. Identidade psicossocial e pessoal como questão contemporânea. Psico, São Paulo, v. 38, n. 1, 2007, p.77-84.

PISCITELLI, A. Gênero: a história de um conceito. In: BUARQUE DE ALMEIDA, H.; SZWAKO, J. (org.). Diferenças, igualdade. São Paulo: Berlendis \& Vertecchia, 2009. p. 116-148.

PNUD - Programa das Nações Unidas para o Desenvolvimento; IPEA - Instituto de Pesquisa Econômica Aplicada; FJP - Fundação João Pinheiro. Desenvolvimento Humano para Além das Médias. Brasília, 2017. Disponível em:

$<$ https://www.ipea.gov.br/portal/images/stories/PDFs/livros/livros/170510_desenvolviment o_humano_para_alem_das_medias.pdf $>$ Acesso em 03 de jul. de 2019.

PREFEITURA DE GUARAPUAVA. Feira do Produtor Rural garante compra de alimentos frescos e aumento de renda de pequenos produtores de Guarapuava. Publicado em 21 de jul de 2017. Disponível em: <Feira do Produtor Rural garante compra de alimentos frescos e aumento da renda dos pequenos produtores de Guarapuava Prefeitura de Guarapuava> Acesso em 06 de out. de 2019.

RAUPP, F. M.; BEUREN, I. M. Metodologia da pesquisa aplicável às ciências: Como elaborar trabalhos monográficos em contabilidade, teoria e prática. São Paulo: Atlas, 2006.

RAWORTH. K. Economia Donut: uma alternativa para o crescimento a qualquer custo. Rio de Janeiro: Zahar, 2019.

SCHNEIDER, S. A pluriatividade na agricultura familiar. Porto Alegre: Editora da UFRGS, 2003. (Série Estudos Rurais).

SEN, A. K. Desenvolvimento como Liberdade. São Paulo: Companhia das Letras. 2000. Trad. Laura Teixeira.

SUCUPIRA, Fernanda. Mulheres do campo construindo autonomia: experiências de comercialização. São Paulo: Sempreviva Organização Feminista, 2016. 36 p.

VALDIVIA, O. B. Psicanálise e feminilidade: algumas considerações. Psicologia: Ciência e Profissão, [s.1.], v. 17, n. 3, 1997, p.20-27.

VERISSIMO, R. Desenvolvimento Psicossocial (Erik Erikson). Porto: Faculdade de Medicina do Porto, 2002. 
WANDERLEY, M. N. B. Agricultura familiar e campesinato: rupturas e continuidade. Estudos Sociedade e Agricultura, Rio de Janeiro, nº . 21, 2003, p. 42-61.

WEDIG, J. C.; TERNOSKI, S.; PERONDI, M. A.; KIYOTA, N. Movimentos de Emigração de Mulheres Rurais em Itapejara d'Oeste/PR: enfrentando relações de poder patriarcais. Redes, Santa Cruz do Sul, v. 26, jan. 2021. 